\title{
PENDAMPINGAN KEGIATAN FUN WITH ENGLISH PADA SERIKAT ANAK MISIONER (SEKAMI) STASI ST. ZAKHARIA, KEUSUKUPAN AGUNG ENDE, FLORES, NTT
}

\author{
Agustina Pali ${ }^{1)}$, Maria Kristina Ota ${ }^{1)}$ \\ ${ }^{1)}$ Program Stusi Pendidikan Guru Sekolah Dasar, Fakultas Keguruan dan Ilmu Pendidikan, Universitas Flores, Ende, NTT, \\ Indonesia \\ Corresponding author : Agustina Pali \\ E-mail :paliagustina18@gmail.com
}

Diterima 09 September 2020, Direvisi 22 September 2020, Disetujui 23 September 2020

\begin{abstract}
ABSTRAK
Bahasa Inggris merupakan bahasa pengantar yang digunakan untuk berkomunikasi diseluruh dunia. Pembelajaran bahasa Inggris untuk pemula (beginners) adalah hal yang harus dilakukan sehingga bisa dijadikan bekal untuk anak dimasa depan. Tujuan dari kegiatan pendampingan ini adalah untuk memperkenalkan bahasa Inggris sejak dini kepada anak-anak serta mampu meningkatkan motivasi serta rasa percaya diri anak-anak dalam menggunakan bahasa Inggris. Salah satu aktivitas yang dilakukan adalah kegiatan Fun with English yang merupakan a recommended activity to motivate kids in learning English dengan menerapkan metode pembelajaran yang beragam sehingga anak-anak tidak merasa jenuh bahkan bosan dalam proses belajar seperti ceramah, Think Pair Share, games serta lagulagu berbahasa Inggris. Dari kegiatan ini anak-anak SEKAMI menjadi merasa percaya diri, pembelajaran yang diberikanpun sangat disenangi oleh anak-anak. Saran bagi pemerhati bahasa Inggris adalah untuk lebih meningkatkan kreativitas melalui berbagai macam cara untuk membumikan bahasa Inggris di bumi nusantara.
\end{abstract}

Kata kunci: fun with English; SEKAMI.

\begin{abstract}
English language is a medium language which used to communicate in all over the world. English learning for the beginners is the important thing that have to do so that it can be supplied for their future. The aim of this activity was to introduce English as early as possible to children and could enhance their motivation and their confidence in using English. One of the activity is Fun with English activity that is a recommended activity to motivate children in learning English by implementing various learning methods in order that the children will never get bored and saturated during learning process. These activities such as lectures, Think Pair Share, games and also English songs. From this activity, the children of SEKAMI become have their self confidence, they felt happy with the materials are given by their teacher. The suggestion is addressed to English observer is they have to be more aware in increasing the creativity through many activities.
\end{abstract}

Keywords: fun with English, SEKAMI

\section{PENDAHULUAN}

Bahasa Inggris menempati posisi urgent dalam dunia dewasa ini. Sebagai Bahasa yang digunakan dalam komunikasi global, program Bahasa Inggris telah ditetapkan secara resmi sejak tahun 1994 dalam sistem pendidikan di Indonesia. Bahasa Inggris disebut sebagai "lingua franca", yakni bahasa Inggris digunakan sebagai bahasa pengantar di dunia(Fromki, Rodman, \& Hyams, 1996; Kirkpatrick, 2011; Hidayati, 2018). Hal ini berarti bahwa bahasa Inggris wajib untuk dipelajari dan dikuasai oleh bagi setiap kalangan.

Diera global seperti sekarang ini, berbagai sumber ilmu pengetahuan dan teknologi, buku teks maupun elektronik pada umumnya berbahasa Inggris. Hal inipun dijumpai di negara kita dengan adanya pembelajaran bahasa Inggris yang diterapkan dari tingkat anak usian dini sampai pada tingkat perguruan tinggi. Selain itu juga, para orang tua mengirimkan anak-anak mereka untuk mengikuti kegiatan ekstra kurikuler atau mengikuti bimbingan belajar bahasa Inggris.

Bahasa Inggris perlu ditanamkan sejak dini karena pada usia dini otak anak berada pada masa plasticity dan flexibility. Pada masa ini memori anak sangatlah bagus untuk merekam dengan baik segala informasi yang diterima oleh otak. Pada usia seperti itu daya 
ingat anak sangat tinggi dibandingkan dengan orang dewasa (Lightfoot, Cole, \& Colle, 2013).. Mengenalkan bahasa Inggris sedini mungkin, berarti membekali serta mempersiapkan anak untuk mengarungi dunia ilmu pengetahuan dan teknologi secara leluasa dengan tetap menjujung tinggi norma-norma yang berlaku.

Membekali dan mempersiapkan anak untuk mempelajari bahasa Inggris membutuhkan keseriusan yakni keseriusan dunia pendidikan dalam mendorong secara penuh kecakapan generasi Indonesia dalam bidang keahlian berbahasa Inggris. Keseriusan ini tidak akan berbuah baik jika tidak didukung penuh oleh kreativitas dari para pemerhati Bahasa Inggris. Kreativitas yang dimaksudkan adalah bagaimana upaya untuk menciptakan aktivitas dan moment belajar Bahasa Inggris secara menyenangkan. Salah satu aktivitas yang dapat dilaksanakan adalah kegiatan Fun with English. Fun with English adalah a recommended activity to motivate kids in learning English. Kegiatan ini melibatkan anakanak yang masih duduk di bangku Sekolah Dasar.

Selain itu juga, kegiatan ini dilaksanakan untuk pengembangan hasil pendidikan dan penelitian kami selaku dosen pengampuh mata kuliah English for Childrendi prodi Pendidikan Guru Sekolah Dasar, Universitas Flores, untuk menggunakan teknik praktis pembelajaranbahasa Inggris yang menyenangkan.

\section{METODE}

Dari kendala yang dialami oleh anakanak SEKAMI pada stasi Zakharia, solusi yang ditemukan adalah degan melakukan pendampingan yang lebih serius pada kegiatan mingguan yang dilakukan anak-anak seperti kegiatan Fun wtih English.

Kegiatan ini bertempat di Aula Gereja St. Zakharia, Watusipi, Paroki St. Maria Worhonio, Keuskupuan Agung Ende, dengan jadwal kegiatannya

Kegiatan pendampingan ini memiiliki beberapa tujuan, antara lain: pertama adalah untuk memperkenalkan bahasa Inggris sejak dini kepada anak-anak SEKAMI (Serikat Anak Missioner) stasi Zakharia, paroki St. Maria Worhonio, Keusukupan Agung Ende, dan yang kedua adalah untuk meningkatkan motivasi dan rasa percaya diri anak-anak SEKAMI dalam menggunakan bahasa Inggris.

Untuk mencapai tujuan tersebut di atas,

Adapun beberapa strategi yang digunakan antara lain: menngadakan kegiatan Fun with English bagi anak-anak SEKAMI (1 kali) dalam sebulan dalam kegiatan Sunday school melalui teknik pembelajaran yang menyenangkan seperti menyanyikan lagu-lagu berbahasa Inggris. Menurut Almutairi \& Shukri, 2016 melalui songs anak-anak akan merasa senang untuk belajar sambil bernyanyi serta membantu anak-anak untuk lebih mengingar kata-kata yang sedang mereka pelajari. (Almutairi \& Shukri, 2016). Sofi, 2015 juga menambahkan bahwa Kegunaan dari movies, songs dan graphic novels adalah untuk memotivasi siswa dan meningkatkan kemauan belajar. Selain itu juga dengan melalui songs perbendaharaan kosakata anak-anak pun bertambah serta didukung dengan games dan hal-hal menarik lainnya untuk memancing keterlibatan anak-anak serta kegiatan ini lebih terasa bermakna. Dengan games anak-anak diberi kesempatan untuk belajar menggunakan bahasa secara bermakna dan membantu guru untuk memahami kebutuhan peserta didiknya (Sari, 2018). Melalui games pula, peserta didik yang malu berbicara, akan diberi motivasi, dilatih dan diberikan kesempatan lebih banyak untuk mengekpresikan ide, gagasan serta perasaan (Sultanova, 2011), meningkatkan motivasi belajar, mengurangi learning anxiet, menciptakan konteks yang bermakna dalam penggunaan bahasa, mengintegrasikan keterampilan linguistik dan mendorong participatory attitudes peserta didik (I-Jung, 2003; Petrovic, 2014; Hang, 2017)

$$
\text { Kegiatan pendampingan ini }
$$

dilaksanakan berdasarkan program dalam rapat pleno stasi Watusipi. Pendampingan dilaksanakan sebanyak satu kali dalam sebulan yakni pada hari minggu tanggal 23 Juni, 21 Juli, 11 Agusutus dan 5 September tahun 2019 dengan jumlah pesertanya adalah 37 orang.

Program kegiatan bulanan meliputi memperkenalkan pada anak English Aphabet, mempelajari kosakata yang berkaitan dengan Part of The Body, Foods and Drinks serta mempelajari Greetings and Farewells.

$$
\text { Dalam melaksakan kegiatan }
$$

pendampingan pembelajaran Fun with English, metode yang digunakan bervariatif, antara lain ceramah, pembelajaran koperatif tipe think pair share, dan juga beberapa teknik belajar lain misalnya menggunakan lagu (song). Metode ceramah digunakan untuk menyampaikan materi secara umum, kemudian dilanjutkan dengan metode pembelajaran koperatif tipe think pair share untuk membantu anak-anak SEKAMI mendalami materi pembelajaran dengan langkah-langkah sebagai berikut:

1. Menjelaskan tujuan pembelajaran yang akan dicapai.

2. Memberikan apersepsi mengenai materi yang akan dipelajari. 
3. Menyampaikan isi materi

4. Memberikan pertanyaan kepada peserta kemudian peserta diberikan waktu untuk berpikir.

5. Peserta berpikir untuk memperoleh jawaban (waktu kurang lebih 3 menit).

6. Peserta diminta untuk berpasangan dengan temannya

7. Peserta berdiskusi dengan pasangannya untuk memecahkan pertanyaan yang diajukan pemateri.

8. Peserta menyampaikan hasil diskusinya di depan aula

9. Pemateri memberikan kesimpulan dan meluruskan jawaban peserta.

\section{Materi Pembelajaran}

\section{English Alphabet}

Setelah mempelajari materi ini, anakanakSEKAMIdapat:

- melafalkan English Alphabet

- mengeja huruf-huruf yang membentuk kata-kata dalam Bahasa Inggris.

\section{Alphabet in English:}

\begin{tabular}{|c|c|}
\hline A & [el] \\
\hline & \\
\hline C & [si:] \\
\hline $\mathrm{D}$ & [di:] \\
\hline $\mathrm{E}$ & [i:] \\
\hline$F$ & [ef] \\
\hline G & [d3i:] \\
\hline $\mathrm{H}$ & [elt] \\
\hline 1 & [al] \\
\hline $\mathrm{J}$ & [dzel] \\
\hline K & [kel] \\
\hline $\mathrm{L}$ & [el] \\
\hline$M$ & [em] \\
\hline $\mathrm{N}$ & [en] \\
\hline 0 & {$[\ddot{\theta}]$} \\
\hline$P$ & [pi:] \\
\hline $\mathrm{Q}$ & [kju:] \\
\hline $\mathrm{R}$ & [a:] \\
\hline$S$ & [es] \\
\hline$T$ & [ti:] \\
\hline U & [ju:] \\
\hline V & [vi:] \\
\hline W & [d^bəlju: \\
\hline$x$ & [eks] \\
\hline Y & [wal] \\
\hline Z & [zed] \\
\hline
\end{tabular}

\section{Exercise:}

1. Ucapkan English Alphabet dengan pengucapan yang tepat!

2. Ejalah huruf-huruf yang membentuk nama anda dengan menggunakan English Alphabet!

\section{Fun with English:}

Let's sing this song:

A B CDEFJHIJKLMN $O P Q R S T \cup \vee W X Y$ and $Z$, now I know my $A B C$, next time let you sing with me.

\section{Parts of the Body}

Tujuan kegiatan:

Setelah mempelajari materi ini, anak-anak SEKAMI dapat:

- Mengenal kosakata yang berhubungan dengan parts of the body

- $\quad$ Menyebutkan kosakata yang berhubungan dengan parts of the body

BODY PARTS' NAME

\begin{tabular}{|l|l|}
\hline Head & \multicolumn{1}{|c|}{ Wrist } \\
\hline Face & Back \\
\hline Hair & Navel \\
\hline Ear & Toes \\
\hline Neck & Ankle \\
\hline Forehead & Instep \\
\hline Beard & Toenail \\
\hline Eye & Waist \\
\hline Nose & Abdomen \\
\hline Mouth & Buttock \\
\hline Chin & Hip \\
\hline Shoulder & Leg \\
\hline Elbow & Thigh \\
\hline Arm & Knee \\
\hline Chest & Foot \\
\hline Armpit & Hand \\
\hline Forearm & Thumb \\
\hline
\end{tabular}

\section{Food and Drinks}

Tujuan kegiatan:

Setelah mempelajari materi ini, anak-anak SEKAMI dapat:

- Mengenal kosakata yang berhubungan dengan Food and Drinks

- Menyebutkan kosakata yang berhubungan dengan Food and Drinks

- Mengetahui ungkapan yang berhubungan dengan menanyakan makanan dan minuman Favorit.

- Menjawab pertanyaan yang berkaitan dengan makanan dan minuman favorit. 


\section{Materi Belajar:}

Jenis-jenis Makanan (Food)

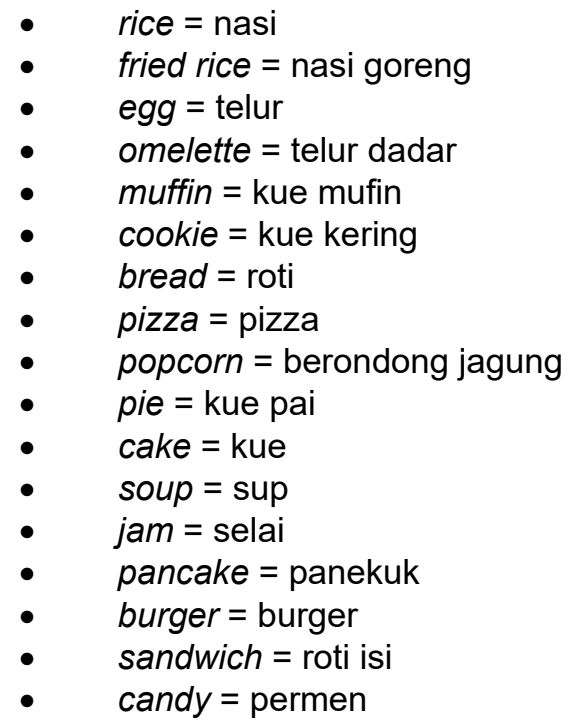

\section{Jenis-jenis Minuman (drinks)}

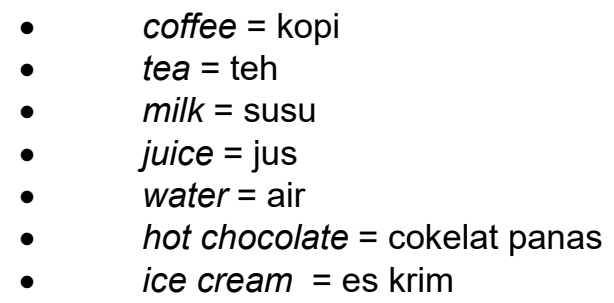

Ungkapan yang digunakan untuk menanyakan makanan favorit:

What is your favourite food?

What is your favourite drink?

Jawaban:

My favourite food is....

My favourite drink is....

\section{Greetings and Farewells}

Tujuan kegiatan:

Setelah mempelajari materi ini, anak-anak SEKAMI dapat:

- Menyapa atau memberikan salam (perjumpaan dan perpisahan)

- Menjawab sapaan atau salam dari teman

- Menanyakan kabar seseorang

- Menjawab pertanyaan tentang kabar
Ada beberapa ungkapan (expression) yang lazim digunakan untuk menyapa seseorang/pada saat berjumpa dan berpisah:

\section{Greetings}

Good morning ((ungkapan ini digunakan untuk memberi salam/sapaan yang diucapkan di pagi hari sebelum pukul 12.00)

Good afternoon: ungkapan ini digunakan apabila kita berjumpa setelah pukul 12.00

Good evening: ungkapan ini digunakan apabila kita berjumpa pada sore hari. Adajuga salam yang diucapkan pada waktu menjelang tidur yaitu (Good Night)

How do you do (first meeting)

Hello, how are you?

$\mathrm{Hi}$

\section{Farewells}

Bye! (Bye-bye!)

See you!

See you later!

See you again!

See you then!

See you tomorrow!

Ketika anda ingin menanyakan dan menjawab pertanyaan tentang kabar, maka anda dapat menggunakan ungkapan-ungkapan berikut:

\section{Questions/Pertanyaan}

How are you?

How's life?

How about you?

How's it going?

How're you doing?

How is your mother?

How are your parents?

How are they?

\section{Answer/Jawaban:}

I am fine, thank you

I am OK

So-so (baik-baik)

Not bad (tidak jelek)

Bad (buruk)

Very well, thank you

Just fine, thank you

So far so good (sejauh ini baik saja)

Apabila seseorang menanyakan kabar dengan menggunakan ungkapan how are you? Maka jawaban yang kita berikan bisa bervariasi, seperti;

Fine, thank you

Just fine, thank you

I'm very well. Thank you 


\section{HASIL DAN PEMBAHASAN}

Kegiatan ini telah dilaksanakan sesuai dengan tempat dan jadwal yang telah disepakati. Pertemuan pertama dilaksanakan pada hari Minggu, pada tanggal 23 Juni 2019 pada saat Sunday School. Materi yang pelajari pada minggu pertama adalah English Alphabet. Hal ini dikarenakan, anak-anak yang terlibat dalam kegiatan ini masih berada pada level beginners, oleh sebab itu pemateri membutuhkan kesabaran ekstra dalam menyampaikan materi Bahasa Inggris yang dilakukan secara berulang. Metode yang digunakan adalah ceramah dan lagu-lagu dalam berbahasa Inggris. Metode ceramah digunakan untuk memberikan materi dan memotivasi anak-anak dalam mempelajari bahasa Inggris, sedangkan penggunaan song dalam pembelajaran dengan topik English Alphabet digunakan untuk menciptakan suasana belajar yang menyenangkan.

Pertemuan kedua, dilaksanakan pada tanggal 21 Juli 2019 yang dilaksanakan pada tempat yang sama. Materi yang dipelajari adalah Parts of the Body. Sebagai pembelajar pemula, anak-anak SEKAMI merasa malu dan takut untuk mengucapkan kosakata-kosakata yang berkaitan dengan topik yang dipelajari. Untuk mengatasi hal ini, maka pemateri menggunakan model pembelajaran Think Pair Share dalam kegiatan ini.Hal yang diperoleh dari pertemuan minggu kedua ini adalah seluruh anak-anak SEKAMlyang terlibat dalam kegiatan ini menjadi termotivasi dan merasa percaya diri untuk mengucapkan kosakatakosakata yang berkaitan dengan materi pebelajran karena terlebih dahulu berdiskusi dan mempersiapkan diri dalam kelompok mereka masing-masing sebelum mempresetasikannya di depan aula.

Pertemuan ketiga, dilaksanakan pada hari minggu tanggal 11 Agustus 2019. Lokasi dan pesertanya masih sama seperti pada pertemuan-pertemuan sebelumnya. Namun pada pertemuan ini topik dari materi pembelajarannya adalah food and Drinks.Tujuan dari kegitan pada pertemuan ketiga ini adalah agar anak-anak SEKAMI dapat mengenal kosakata yang berhubungan dengan Food and Drinks, menyebutkan kosakata yang berhubungan dengan Food and Drinks, mengetahui ungkapan yang berhubungan dengan menanyakan makanan dan minuman favorit serta dapat menjawab pertanyaan yang berhubungan dengan menanyakan makanan dan minuman favorit. Untuk mencapai tujuan ini maka pemateri selaku instruktur kegiatan memilih model belajar Think Pair Share seperti yang telah diterapkan pada pertemuan sebelumnya. Penggunaan metode ini dapat membuat kegiatan belajar menjadi lebih menyenangkan dan bahasa Inggris untuk para pemula ini menjadi tidak menakutkan.

Pertemuan keempat, dilaksanakan pada tanggal 15 september 2019. Materi yang dipelajari adalah Greeting and Farewells. Tujuan dari pertemuan ini adalah setelah mempelajaru materi ini, anak-anak SEKAMI dapat menggunakan ekpresi dalam hal menyapa dan memberikan salam (perjumpaan dan perpisahan), dapat menjawab sapaan atau salam dari teman, dapat menanyakan kabar seseorang serta dapat menjawab pertanyaan tentang kabar. Untuk mencapai tujuan pembelajaran ini makan pertemuan diawali dengan penjelasan materi dengan menggunakan metode ceramah kemuadian dilanjutkan dengan model pembelajaran Think Pair Share. Antusiasme anak-anak sangat keliahatan pada moment ini karena adanya keakraban yang terjalin dengan dunia bahasa Inggris yang sudah mereka pelajari selama empat minggu, ketakutan-ketakutan yang kelihatan pada pertemuan sebelumnya sudah berangsur menghilang. Kegiatan ini diakhiri dengan nyanyian dan games sehingga anakanak merasa bahwa pembelajaran semakin menyenangkan. Anak-anakpun meminta agar pertemuan ini tidak dilaksanakan hanya sebulan sekali namun dilaksanakan setiap minggu. Namun, hal ini masih dipertimbangkan oleh instruktur.

\section{SIMPULAN DAN SARAN \\ Simpulan}

Kegiatan Fun with English yang diimbangi dengan pemilihan metode, model maupun teknik pembelajaran yang menarik merupakan kegiatan yang sangat menyenangkan bagi pembelajar pemula bahasa Inggris (the beginners) seperti yang terjadi pada anak-anak SEKAMI. Pembelajaran bahasa Inggris yang awalnya menakutkan akan berubah menjadi topik yang sangat disenangi bahkan dirindukan oleh anak-anak SEKAMI. Oleh karena itu kami menyarankan agar semua pemerhati bahasa Inggris, lebih meningkatkan kreativitas melalui berbagai macam cara, salah satunya adalah dengan melaksanakan kegiatan Fun with English untuk membumikan bahasa Inggris di Bumi Nusantara.

\section{Saran}

Kegiatan ini sebaiknya dibuat atau dilaksanakan secara berkelanjutan sehingga anak-anak dapat terus mengasah kemampuan mereka dalam berbahasa Inggris. Demikian juga untuk waktunya, diharapkan untuk menambah jumlah pertemuan atau tatap muka. 


\section{DAFTAR RUJUKAN}

Almutairi, M., \& Shukri, N. (2016). Using Songs in Teaching Oral Skills to Young Learners: Teachers ' Views and Attitudes. International Journal of Linguistics, $\quad 8(6)$, 133-153. https://doi.org/10.5296/ijl.v8i6.10464

Fromki, V., Rodman, R., \& Hyams, N. (1996). An introduction to language. In Revue Française d'Etudes Américaines (Vol. $67)$. https://doi.org/10.3406/rfea.1996.1625

Hang, S. (2017). Using Games to teach Young Children English Language: Teachers' primary purpose of and their perceptions on using games when teaching English language to young children. Retrieved from https://www.researchgate.net/publicati on/320345809_Using_Games_to_teac h_Young_Children_English_Language

Hidayati, $\bar{N}$. N. (2018). Pentingnya Peningkatan Kompetensi Bahasa Inggris bagi Guru Anak Usia Dini. Journal Of Early Childhood Islamic Education, 2(1), 5974.

I-Jung, C. (2003). Using Games to Promote Communicative Skills in Language Learning. The Internet TESL Journal, 11(2), 1-4. Retrieved from http://iteslj.org/Techniques/ChenGames.html

Kirkpatrick, A. (2011). World Englishes: Implications for International Communication and English Language Teaching. World Englishes, p. 256. Retrieved from http://books.google.com/books?id=qPu vcQAACAAJ\&pgis $=1$

Lightfoot, C., Cole, M., \& Colle, R. S. (2013). The development of children (Seventh). https://doi.org/10.1017/CBO97811074 15324.004

Petrovic, E. P. (2014). Examensarbete Games in the Language Classroom-To Play is to Learn. Retrieved from http://citeseerx.ist.psu.edu/viewdoc/do wnload?doi=10.1.1.921.6777\& $\mathrm{rep}=\mathrm{rep}$ 1 \&type $=$ pdf

Sari, E. P. (2018). The use of games as a strategy to teach English to young learners (SANATA DHARMA UNIVERSITY YOGYAKARTA). Retrieved from https://repository.usd.ac.id/23936/2/13 1214087_full.pdf

Sofi, L. A. (2015). Teaching English in Saudi Arabia Through the Use of Multimedia (UNIVERSITY of SAN FRANCISCO). https://doi.org/Master's Projects
Sultanova, D. T. (2011). The use of games in learning english grammar. Proceeding of Uzbek-Indonesian Joint International Conference, Gunadarma University Jakarta, 1, 978-979. Retrieved from https://core.ac.uk/download/pdf/14396 4197.pdf 